\title{
Pannexin 2 protein expression is not restricted to the CNS
}

\section{Maxence Le Vasseur, Jonathan Lelowski, John F. Bechberger, Wun-Chey Sin and Christian C. Naus*}

Department of Cellular and Physiological Sciences, The Life Science Institute, University of British Columbia, Vancouver, BC, Canada

\section{Edited by:}

Juan Andrés Orellana, Pontificia

Universidad Católica de Chile, Chile

Reviewed by:

Georg Zoidl, York University, Canada Valery I. Shestopalov, University of Miami Miller School of Medicine,

USA

\section{*Correspondence:}

Christian C. Naus, Department of Cellular and Physiological Sciences, The Life Science Institute,

University of British Columbia, 2350

Health Science Mall, Vancouver, BC V6T 1Z3, Canada

e-mail:christian.naus@ubc.ca
Pannexins (Panx) are proteins homologous to the invertebrate gap junction proteins called innexins $(\operatorname{Inx})$ and are traditionally described as transmembrane channels connecting the intracellular and extracellular compartments. Three distinct Panx paralogs (Panx1, Panx2 and Panx3) have been identified in vertebrates but previous reports on Panx expression and functionality focused primarily on Panx1 and Panx3 proteins. Several gene expression studies reported that Panx2 transcript is largely restricted to the central nervous system (CNS) hence suggesting that Panx2 might serve an important role in the CNS. However, the lack of suitable antibodies prevented the creation of a comprehensive map of Panx2 protein expression and Panx2 protein localization profile is currently mostly inferred from the distribution of its transcript. In this study, we characterized novel commercial monoclonal antibodies and surveyed Panx2 expression and distribution at the mRNA and protein level by real-time qPCR, Western blotting and immunofluorescence. Panx2 protein levels were readily detected in every tissue examined, even when transcriptional analysis predicted very low Panx2 protein expression. Furthermore, our results indicate that Panx2 transcriptional activity is a poor predictor of Panx2 protein abundance and does not correlate with Panx2 protein levels. Despite showing disproportionately high transcript levels, the CNS expressed less Panx2 protein than any other tissues analyzed. Additionally, we showed that Panx2 protein does not localize at the plasma membrane like other gap junction proteins but remains confined within cytoplasmic compartments. Overall, our results demonstrate that the endogenous expression of Panx2 protein is not restricted to the CNS and is more ubiquitous than initially predicted.

Keywords: pannexin 2, gap junction, gene transcription, protein expression, protein distribution, central nervous system (CNS), mouse, mRNA

\section{INTRODUCTION}

Gap junction proteins are traditionally described as aqueous plasma membrane channels which allow rapid cell-to-cell communication by directly connecting the cytoplasm of adjacent cells. In chordates, connexins (Cxs) are the canonical gap junction proteins while gap junctions in invertebrates are formed exclusively by the evolutionarily unrelated innexin (Inx) family. In 2000, another small gene family named pannexin (Panx) was identified based on sequence homology with the Inx family and was found to be expressed alongside Cxs in chordates (Panchin et al., 2000). Three distinct Panx paralogs (Panx1, Panx2 and Panx3) were initially identified in vertebrates (Panchin et al., 2000; Panchin, 2005; Barbe, 2006) but recent studies showed that Panxl has been retained as two independent ohnologs in teleost as a result of an ancestral whole genome duplication (Bond et al., 2012; Kurtenbach et al., 2013). Despite the lack of

Abbreviations: Cx, connexin; Inx, innexin; Panx, pannexin; qPCR, quantitative real-time PCR; GFAP, glial fibrillary acidic protein; HRPO, horseradish peroxidase; DEPC, diethylpyrocarbonate; Polr2a, DNA-directed RNA polymerase II subunit RPB1; SDS-PAGE, sodium dodecyl sulfate polyacrylamide gel electrophoresis; BCA, bicinchoninic acid; TCE, 2,2,2-trichloroethanol; NCL, nitrocellulose; PB, phosphate buffer. sequence similarity between Inxs/Panxs and Cxs, both families share structural resemblance. Cxs and Panxs both have a predicted topology consisting of four membrane-spanning domains, two extracellular loops, a cytoplasmic loop, and cytoplasmic $\mathrm{N}$ - and C-termini (Panchin, 2005). Despite sharing structural resemblance with Cxs, the ability of Panx channels to form gap junctional coupling remains controversial. A few groups reported that Panx1 and Panx3 can form cell-cell junctional channels (Bruzzone et al., 2003; Vanden Abeele et al., 2006; Lai et al., 2007; Ishikawa et al., 2011; Sahu et al., 2014) but their observations were limited primarily to heterologous or over-expression systems and undisputable evidence supporting Panx-based coupling is still lacking. In contrast to Cxs, all three Panxs are glycosylated at their extracellular loops (Penuela et al., 2009) with carbohydrate moieties that sterically hinder the docking of channels from adjacent cells (Boassa et al., 2007). Therefore, it is largely accepted that under physiological conditions, Panx channels primarily form non-junctional membrane channels controlling the exchange of ions and small molecules between the cytoplasm and extracellular space and do not significantly contribute to direct cell-to-cell gap junctional communication (Sosinsky et al., 2011). 
Several gene expression profiling studies reported that Panx2 transcriptional activity is largely restricted to the central nervous system in human (Baranova et al., 2004), rat (Bruzzone et al., 2003) and zebrafish (Zoidl et al., 2008; Bond et al., 2012). Minimal Panx2 mRNA levels have also been detected in some non-neural tissues such as the eye, thyroid, prostate, kidney, liver, heart and olfactory epithelium (Bruzzone et al., 2003; Dvoriantchikova et al., 2006; Bond et al., 2012; Zhang et al., 2012) but given the much larger Panx2 mRNA levels found in the CNS, Panx2 transcript and corresponding protein are largely assumed to be primarily expressed in the CNS. In the healthy brain, Panx2 protein was shown to have a complex distribution pattern and is expressed in pyramidal cells and interneurons alike (Zappalà et al., 2007). Interestingly, Panx 2 protein was also detected in astrocytes following ischemia in the rat but not in the healthy brain (Zappalà et al., 2007). Panx2 protein is also present in hippocampal neural progenitors and mature neurons both in vitro and in vivo (Swayne et al., 2010). However, because Panx2 is believed to be primarily CNS-specific, the mapping of Panx2 protein distribution in other tissues has not been undertaken.

In this study, we compared Panx2 gene transcription and protein expression profiles in mouse tissues using a combination of real-time qPCR, Western blot and immunofluorescence. Our results reveal that Panx 2 mRNA and protein levels are not correlated and demonstrate that Panx2 protein expression is more ubiquitous than initially predicted.

\section{MATERIALS AND METHODS ANIMAL CARE}

All experiments were performed in accordance with the guidelines established by the Canadian Council on Animal Care and were approved by the University of British Columbia Animal Care Committee (protocol number A11-0169).

\section{ANTIBODIES}

The two Panx2 mouse monoclonal antibodies (clones N121A/1 and N121A/31) were generated by UC Davis/NIH NeuroMab Facility (Davis, CA, USA) using an immunogen made of the entire rat Panx2 protein sequence (accession number P60571) minus the first 10 amino acids. Both clones were used at $20 \mu \mathrm{g} / \mathrm{mL}$ for immunofluorescence and $5 \mu \mathrm{g} / \mathrm{mL}$ for Western immunoblotting or dot blotting. The rabbit anti-Panx1 polyclonal antibody was generously provided by Dr. Dale Laird from the University of Western Ontario (London, ON, Canada) and was used at $2 \mu \mathrm{g} / \mathrm{mL}$ for immunofluorescence and $0.4 \mu \mathrm{g} / \mathrm{mL}$ for Western immunoblotting. The rabbit anti-GFAP (Sigma, St. Louis, MO, USA) was used at 1:500. Purified immunoglobulin from nonimmunized mouse was obtained from Jackson Immunoresearch (cat\# 015-000-003; West Grove, PA, USA) and was used at the same concentration as the anti-Panx2 antibodies. AlexaFluor- and HRPO-conjugated goat secondary antibodies were obtained from Invitrogen (Carlsbad, CA, USA) and Sigma (St. Louis, MO, USA) respectively.

\section{CELL CULTURE}

Wild-type C6 glioma cells as well as C6-Panx1GFP, C6-Panx2 and C6-Panx2GFP stable transfectants were cultured as previously described (Lai et al., 2007, 2009). Briefly, cells were grown in low glucose DMEM (Sigma-Aldrich, St. Louis, MO, USA) containing $10 \%$ fetal bovine serum, 10 units/mL penicillin, and $10 \mu \mathrm{g} / \mathrm{mL}$ streptomycin at $37^{\circ} \mathrm{C}$ and $5 \% \mathrm{CO}_{2}$. Primary cultures of astrocytes were prepared as previously described (Le et al., 2014). Briefly, cortices were dissected from early postnatal (P0-P1) mouse pups, freed of meninges, minced and mechanically triturated in DMEM. The cell suspension was then strained through a $70 \mu \mathrm{m}$ filter and seeded into T75 flasks (2 cortices/flask). Cells were cultured in DMEM (Sigma-Aldrich, St. Louis, MO, USA) containing $10 \%$ fetal bovine serum, 10 units $/ \mathrm{mL}$ penicillin, and $10 \mu \mathrm{g} / \mathrm{mL}$ streptomycin at $37^{\circ} \mathrm{C}$ and $5 \% \mathrm{CO}_{2}$ and the medium was initially replaced 3 days after plating and every other day subsequently. After 7-8 days, the flasks were vigorously shaken to remove loosely attached cells and primary astrocytes were harvested with trypsin-EDTA (Invitrogen, Carlsbad, CA, USA) and frozen in DMEM, 10\% FBS, and 8\% DMSO. Frozen astrocytes were thawed and plated on glass coverslips coated with poly-L-ornithine ( $0.01 \%$ solution, Sigma-Aldrich, St. Louis, MO, USA). Cultures were maintained for 5, 10 or 15 days prior to staining. The percentage of Panx2-positive astrocytes was defined as the number of cells that stained positively for Panx2 divided by the number of nuclei. For each time point, that ratio was calculated by averaging the values obtained from three coverslips with 10 field of views $(168 \times 225 \mu \mathrm{m})$ per coverslip.

\section{EPITOPE MAPPING}

A library of 70 overlapping peptides covering the entire sequence of the rat Panx2 (Uniprot accession number P60571) minus the four transmembrane domains was obtained from Genscript (Piscataway, NJ, USA). Peptides were 15 amino acids in length with a 7 amino acids overlap. A total of $100 \mu \mathrm{g}$ of peptide was pre-incubated overnight at $4^{\circ} \mathrm{C}$ in $100 \mu \mathrm{L}$ of dot-blot buffer (8 M Urea, $100 \mathrm{mM} \mathrm{NaH} \mathrm{PO}_{4}, 10 \mathrm{mM}$ Tris, $\mathrm{pH}$ 8.0) containing $10 \mu \mathrm{g}$ bovine serum albumin. Peptides were then dotblotted on nitrocellulose membrane (Bio-Rad, Hercules, CA, USA), washed with sodium phosphate buffered saline (PBS, $\mathrm{pH}$ 7.4), dried at $37^{\circ} \mathrm{C}$ and blocked for $1 \mathrm{~h}$ in milk solution (4\% nonfat milk, $20 \mathrm{mM}$ Tris, $150 \mathrm{mM} \mathrm{NaCl} \mathrm{pH} \mathrm{7.4).} \mathrm{The} \mathrm{mem-}$ brane was then immunoprobed for $2 \mathrm{~h}$ at room temperature with the primary antibody followed by HRPO-conjugated secondary antibodies (Sigma, St. Louis, MO, USA) for $1 \mathrm{~h}$ at room temperature.

\section{RNA ISOLATION AND REAL-TIME QUANTITATIVE PCR}

Three 3-5 month old mice were deeply anesthetized by intraperitoneal injection of sodium pentobarbital and perfused transcardially with $10-15 \mathrm{~mL}$ of PBS ( $\mathrm{pH} 7.4$ ) followed by $10-15 \mathrm{ml}$ of aqueous ammonium sulfate solution (5.3 M ammonium sulfate, $25 \mathrm{mM}$ sodium citrate, $10 \mathrm{mM}$ EDTA, pH5.2) to precipitate degenerative RNases. Organs were rapidly harvested and stored at $-80^{\circ} \mathrm{C}$ in the same solution. Total RNA was harvested from $50 \mathrm{mg}$ of tissue using Trizol Reagent (Invitrogen, Carlsbad, CA, USA) according to the manufacturer's directions. Air-dried RNA samples were re-solubilized in DEPCtreated double distilled $\mathrm{H}_{2} \mathrm{O}$ and RNA quantity and purity was 
assessed using a NanoDrop 1000 Spectrophotometer (Thermo Scientific, Waltham, MA, USA). All samples had A260/280 and A260/230 ratios above 1.9 and 2.3 respectively. A total of $500 \mathrm{ng}$ per sample was reverse transcribed into cDNA in a $10 \mu \mathrm{L}$ reaction volume using qScript (Quanta Biosciences, Gaithersburg, MD, USA) according to the manufacturer's instructions. Real-time qPCR was performed in $18 \mu \mathrm{L}$ reaction volume containing $45 \mathrm{ng}$ of cDNA and $0.4 \mu \mathrm{M}$ primers diluted in $2 \times$ Fast Plus EvaGreen ${ }^{\circledR}$ qPCR Master Mix (Biotium Inc., Hayward, CA, USA). The following primer pairs were used to amplify Panx2 cDNA (forward 5'-AGAAGGCCAAGACTGAGGCG-3' and reverse $5^{\prime}$ - GGAGCATCTTTGGTGGGTGC-3') and the reference gene DNA-directed RNA polymerase II subunit (RPB1) (Polr2a) cDNA (forward 5'-AGCTGGTCCTTCGAATCCGC-3' and reverse $5^{\prime}$ - TGGACTCAATGCATCGCAGGA-3'). Primers were designed to span an exon junction to prevent amplification of genomic DNA. Samples were amplified in duplicate using the CFX96 RealTime PCR Detection System (Bio-Rad, Hercules, CA, USA) with the following cycling scheme: $2 \mathrm{~min}$ at $95^{\circ} \mathrm{C}$ followed by 50 cycles consisting of $5 \mathrm{~s}$ denaturation at $95^{\circ} \mathrm{C}, 5 \mathrm{~s}$ annealing at $60^{\circ} \mathrm{C}$ and $25 \mathrm{~s}$ elongation at $72^{\circ} \mathrm{C}$. Raw data were exported as text files and analyzed with the qPCR package for R (Ritz and Spiess, 2008). Amplification efficiencies and $\mathrm{Cy} 0$ crossing points (Guescini et al., 2008) were calculated from a 5-parameter log-logistic model fitted to the raw fluorescence data to accommodate asymmetrical amplification curves (Spiess et al., 2008). Values from duplicated qPCR runs were averaged. Expression ratios were calculated from three biological replicates by the Pfaffl method to correct for variation in PCR efficiency (Pfaffl, 2001) and normalized against the reference gene Polr2a. Spinal cord mRNA levels were used as baseline to compare Panx 2 expression across tissues. Propagation of error was estimated by a Monte Carlo simulation with 10,000 iterations as described in the qPCR package documentation.

\section{PROTEIN ISOLATION AND WESTERN BLOTTING}

Organs were quickly collected after transcardial perfusion with PBS, flash frozen in liquid nitrogen and stored at $-80^{\circ} \mathrm{C}$ until needed. Tissues or cells were homogenized in RIPA buffer (150 mM NaCl, 50 mM Tris- $\mathrm{HCl}$ pH 8.0, 0.5\% Sarkosyl, 1\% IGEPAL, $0.1 \%$ SDS) containing protease inhibitors (Pierce, Rockford, IL, USA) and phosphatase inhibitors (Sigma, St. Louis, MO, USA). Protein concentration was determined using a bicinchoninic acid (BCA) assay kit (Pierce, Rockford, IL, USA) and $50 \mu \mathrm{g}$ was separated on $10 \%$ Tris-glycine SDS-PAGE gels containing 0.5\% 2,2,2-trichloroethanol (TCE; Sigma, St. Louis, MO, USA). Upon electrophoresis completion, protein bands were visualized at $300 \mathrm{~nm}$ on an AlphaImager 3400 transilluminator (AlphaInnotech, San Leandro, CA, USA) as previously described (Ladner et al., 2004) and electroblotted on nitrocellulose (NCL) membrane (Bio-Rad, Hercules, CA, USA). Protein bands on NCL were re-visualized under UV for quantification and total protein normalization (Gürtler et al., 2013). For analysis which did not require quantification, TCE was omitted and PVDF membranes were used (Bio-Rad, Hercules, CA, USA). Membranes were blocked at room temperature for $1 \mathrm{~h}$ in milk solution (4\% nonfat milk, $20 \mathrm{mM}$ Tris, $150 \mathrm{mM} \mathrm{NaCl}, \mathrm{pH} \mathrm{7.4)}$ and probed with primary antibodies at $4^{\circ} \mathrm{C}$ overnight followed by
HRPO-conjugated secondary antibodies (Sigma, St. Louis, MO, USA) for $1 \mathrm{~h}$ at room temperature. All antibodies were diluted in blocking solution. HRPO activity was visualized with Amersham ECL Prime Western Blotting Detection Reagent (GE Healthcare Life Sciences, Pittsburgh, PA, USA) or SuperSignal West Femto Chemiluminescent Substrate (Thermo Scientific, Waltham, MA, USA) and exposed on Bioflex Econo films (Clonex, Markham, $\mathrm{ON}$, Canada). Image acquisition for Western blot quantification was done as previously described (Gassmann et al., 2009). Briefly, film images were acquired on an AlphaImager 3400 (AlphaInnotech, San Leandro, CA, USA) under stable transillumination and fitted with CCD camera lacking automatic gain control. Final 16-bit $1392 \times 1040$ pixel images were corrected for shading to compensate for non-homogenous illumination and densitometry analysis was performed using the Image Studio Lite software (LI-COR, Lincoln, NE, USA). Panx2 protein ratios were calculated by dividing the band density of each tissue by the band density of the spinal cord. A tissue lysate from spinal cord was resolved on each gel to permit between gel comparisons. Panx2 protein ratios were calculated from three independent biological replicates.

\section{IMMUNOFLUORESCENCE}

Three 3-5 month old mice were transcardially perfused with PBS followed by $10-15 \mathrm{~mL} 10 \%$ formalin (Fisher) or $4 \%$ paraformaldehyde (PFA) in PBS. Tissues were rapidly harvested and postfixed overnight at $4^{\circ} \mathrm{C}$ in the same fixative. Tissues were equilibrated at $4^{\circ} \mathrm{C}$ in $30 \%$ sucrose in PBS containing $0.05 \%$ sodium azide for cryoprotection, embedded in TissueTek O.C.T. compound (Sakura Finetek, Torrance, CA, USA), frozen, cryosectioned at $10 \mu \mathrm{m}$ thickness and air-dried. Tissue sections were rehydrated in $0.1 \mathrm{M}$ phosphate buffer ( $\mathrm{PB}$, $\mathrm{pH}$ 7.4), post-fixed with 4\% PFA for $10 \mathrm{~min}$ and washed twice with PB. Antigen retrieval was performed by incubating the sections in $10 \mathrm{mM}$ sodium citrate $(\mathrm{pH} \mathrm{8.5)}$ at $80^{\circ} \mathrm{C}$ for $30 \mathrm{~min}$. Sections were cooled to room temperature, washed with $\mathrm{PB}$ and treated with $1 \%$ sodium borohydride in $\mathrm{PB}$ for $30 \mathrm{~min}$. After several washes in $\mathrm{PB}$, samples were blocked for $1 \mathrm{~h}$ at room temperature with $5 \%$ goat serum in $\mathrm{PB}$ containing $0.2 \%$ Triton $\mathrm{X}-100$ and incubated overnight at $4{ }^{\circ} \mathrm{C}$ in primary antibody diluted in $1 \%$ goat serum in $\mathrm{PB}$. Sections were then washed in $\mathrm{PB}$ and incubated for $1 \mathrm{~h}$ at room temperature with the appropriate AlexaFluor 488 or 568 secondary antibodies (Invitrogen, Carlsbad, CA, USA), followed by mounting in ProLong Gold antifade reagent with DAPI (Invitrogen). Cells grown on coverslips were simply fixed with 4\% PFA for 15-20 min prior blocking and immunostaining. Imaging was performed on a Leica TCS SP5 confocal microscope (Leica, Mannheim, Germany). When indicated, images were further processed with an iterative Lucy-Richardson deconvolution algorithm (Vonesch and Unser, 2008). All images were displayed as individual optical sections taken from a $\mathrm{z}$-stack and not as maximal projection. All image acquisition and post-acquisition processing steps were kept constant when comparing sections stained with antiPanx2 antibodies and immunoglobulins from non-immunized animal. 


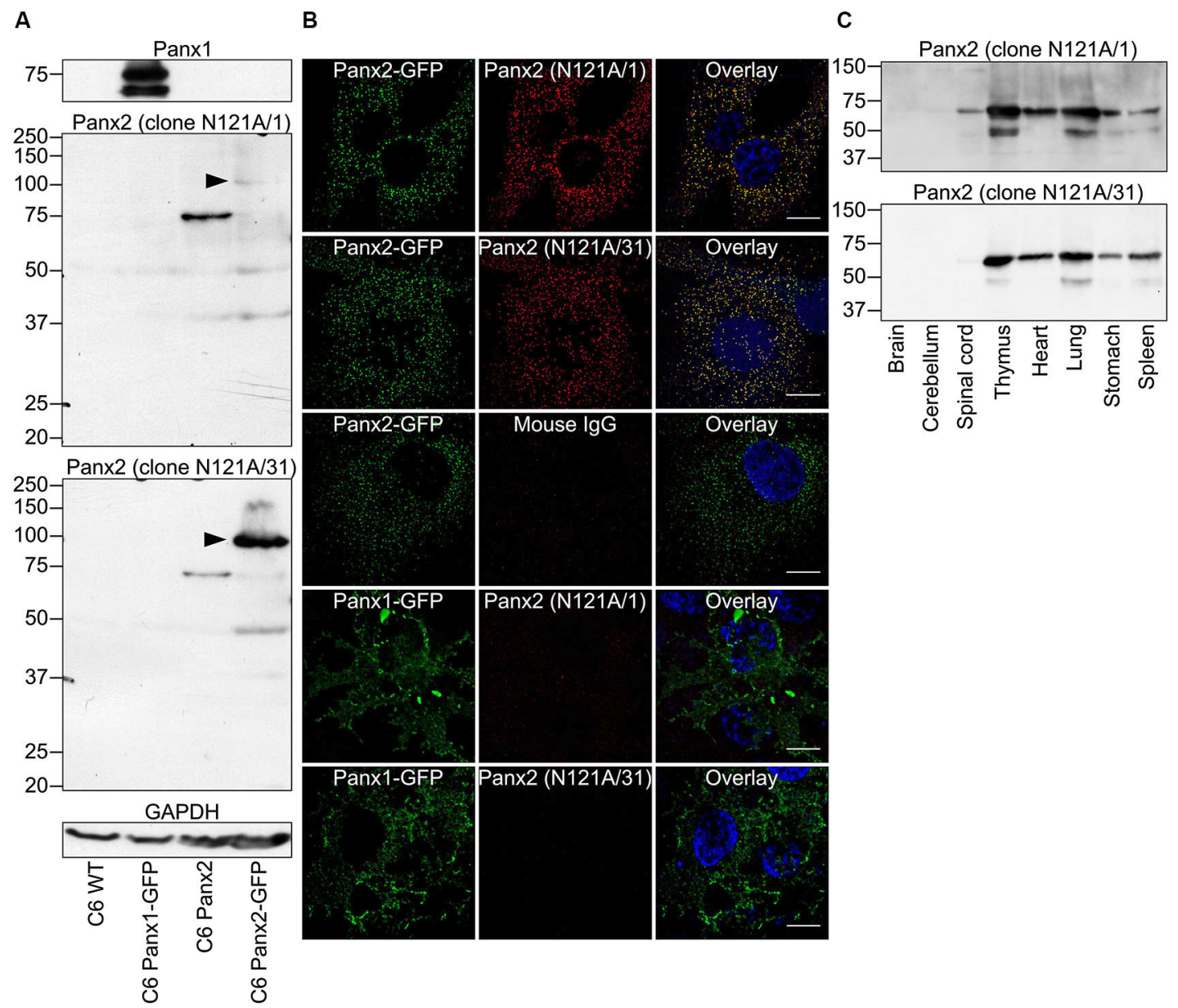

FIGURE 1 | Specificity of two novel anti-Panx2 monoclonal antibodies. Two anti-Panx2 monoclonal antibodies (clones N121A/1 and N121A/31) showed high specificity both in Western blot $(\mathbf{A}, \mathbf{C})$ and immunolabeling (B). (A) Both clones detected a single band of the proper size in $\mathrm{C} 6$ cells overexpressing Panx2 but did not cross-react with Panx1 or identify unspecific protein bands in wild-type C6 cells. The molecular weight of the protein identified by both clones shifted by $\sim 27 \mathrm{kDa}$ when the Panx2 C-terminal was tagged with GFP (black arrowheads). Interestingly, the avidity of clone $\mathrm{N} 121 \mathrm{~A} / 1$ was drastically reduced when the Panx2 was tagged with GFP. This is explained by the fact that clone N121A/1 recognizes an epitope immediately adjacent to the GFP tag (Figure 2). (B) Immunolabeling signal from both clones co-localized with GFP fluorescence emitted from Panx2GFP but not Panx1GFP when expressed in C6 cells. Immunoglobulin from non-immunized mouse did not give any signal thereby ruling out the possibility of unspecific binding of mouse IgG. Scale bars $=20 \mu \mathrm{m}$. (C) Both clones were equally specific in Western blot performed with various tissue lysates and identified a protein of $\sim 70 \mathrm{kDa}$. The occasional detection of a $\sim 50 \mathrm{kDa}$ band in some tissues suggest that the antibodies might recognize Panx2 degradation products or alternatively that the anti-mouse secondary antibody detects endogenous immunoglobulin heavy chains.

\section{RESULTS}

\section{CHARACTERIZATION OF TWO NOVEL MONOCLONAL ANTIBODIES SPECIFIC FOR Panx2}

We initially characterized the selectivity of two novel anti-Panx2 monoclonal antibodies (N121A/1 and N121A/31) by showing that both clones identified a single band of the proper size in C6 cells overexpressing rat Panx2 (Figure 1A). Importantly, none of the antibody cross-reacted with Panx1 (Figure 1A) which has been shown to be co-expressed with Panx2 in the CNS (Vogt et al., 2005). Selectivity was further supported by an electrophoretic mobility assay showing that the band identified by both clones shifted by $\sim 27 \mathrm{kDa}$ when the Panx2 C-terminal tail was tagged with GFP (Figure 1A). Intriguingly, tagging Panx2 with GFP decreased the avidity of clone N121A/1. Using a library of overlapping peptides covering the amino acid sequence of Panx2, we mapped the epitope of clone N121A/1 to the last 15 amino acids of the Panx2 C-terminal tail (Figure 2). It is therefore likely that the addition of a GFP tag adjacent to the epitope caused steric hindrance and reduced the avidity of clone N121A/1. We also tested the antibodies by immunofluorescence and showed that the labelling from both clones overlapped with the GFP fluorescence signal emitted by Panx2-GFP but not by Panx1-GFP (Figure 1B).

To test whether the novel antibodies could also be used on samples expressing endogenous Panx2 protein we immunoprobed protein lysates prepared from eight tissues and separated by SDS-PAGE (Figure 1C). Our results show that both clones 
A

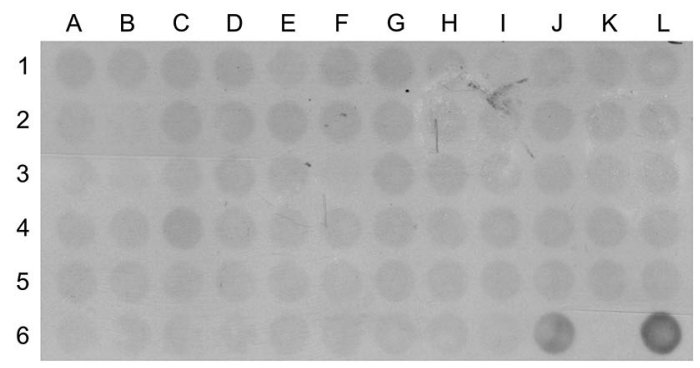

B

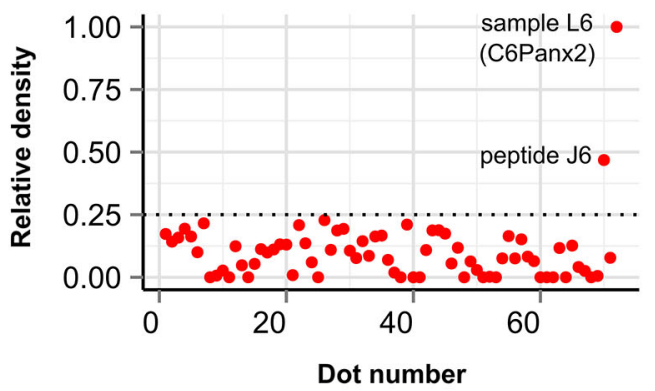

C

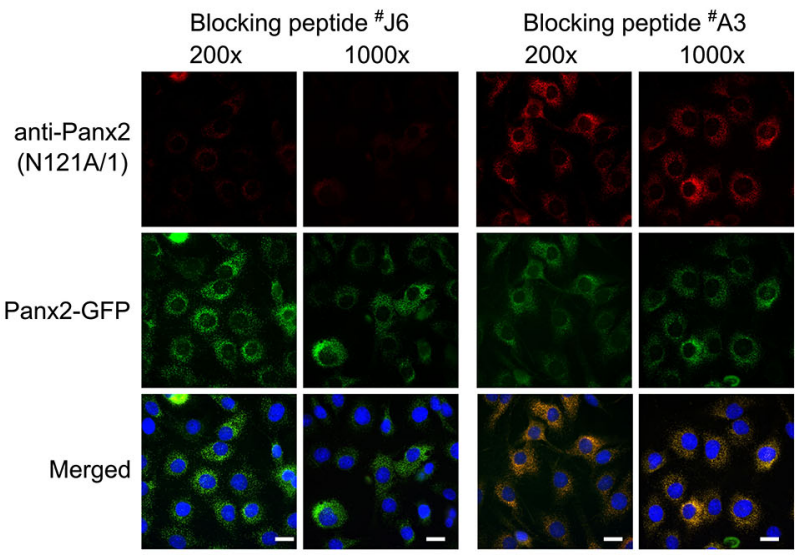

FIGURE 2 | Clone N121A/1 recognizes an epitope located within the last $\mathbf{1 5}$ amino acids of the Panx2 C-terminal. (A) A library of 70 overlapping peptides spanning the entire Panx2 amino acid sequence minus the four transmembrane domains was dot blotted (A1 to J6) and immunoprobed with the N121A/1 anti-Panx2 antibody. A total of $25 \mu \mathrm{g}$ of protein lysate from wild-type C6 and C6Panx2 glioma cells (K6 and L6 respectively) was also dot blotted alongside peptides to provide negative and positive control respectively. The clone N121A/1 specifically recognized C6Panx2 protein lysate and peptide J6 corresponding to the last 15 amino acids of the Panx2 C-terminal (TFEEPRTVVSTVEF). (B) Densitometry analysis of the dot blot staining shown in (A). Only peptide J6 showed signal above threshold. Values were normalized against the density of the C6Panx2 sample. (C) The epitope identity was further confirmed by a blocking peptide assay. Pre-absorbing the N121A/1 anti-Panx2 antibody with a 200 - or 1000-fold molar excess of peptide J6 dramatically reduced immunolabeling while pre-absorption with a peptide randomly selected along the Panx2 amino acid sequence (peptide A3) did not alter the labeling intensity. Scale bars $=20 \mu \mathrm{m}$. recognized a band of approximately $70 \mathrm{kDa}$ corresponding to the expected size of endogenous Panx2 as previously reported (Zappalà et al., 2007; Figure 1C). Overall our results identified two different commercial monoclonal antibodies specific for Panx2. Both clones recognize rat and mouse Panx2 and we also successfully used clone N121A/1 to detect human Panx2 (data not shown). To avoid redundancy and because both clones were equally specific we selected clone N121A/1 for subsequent analysis.

\section{Panx2 HAS A UBIQUITOUS PROTEIN EXPRESSION PROFILE}

Interestingly our initial results showed substantial Panx2 protein amount outside the nervous system (Figure 1C). To further compare the Panx 2 protein expression profile of different tissues, we carried out semi-quantitative densitometry analysis on protein lysates obtained from 16 tissues, separated by SDS-PAGE and immunoprobed for Panx2 (Figure 3A). Because the expression of common reference proteins was subjected to important fluctuations across tissues (data not shown), a stain-free total protein 


\section{A}
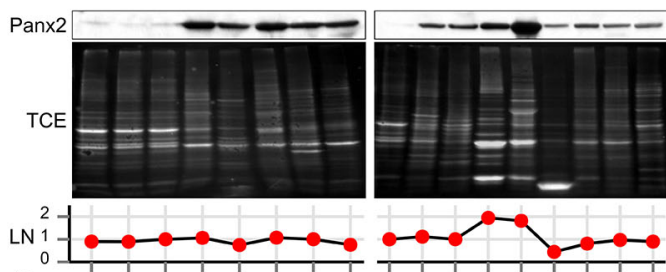

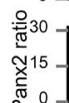

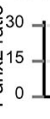

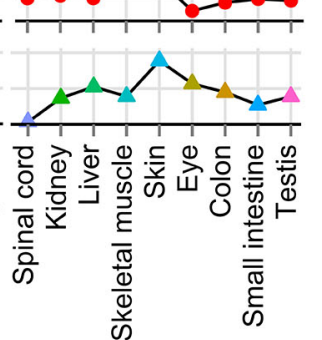

FIGURE 3 | Panx2 protein is ubiquitously expressed. (A) Panx2 protein levels were semi-quantified in 16 tissues using stain-free total protein quantification to normalize protein levels across samples. Following exposure to TCE and UV, protein bands electroblotted on nitrocellulose (NTC) were visualized by fluorescence (TCE, second panel) and loading normalization (LN) was performed by dividing the fluorescence density from an entire individual

\section{B}

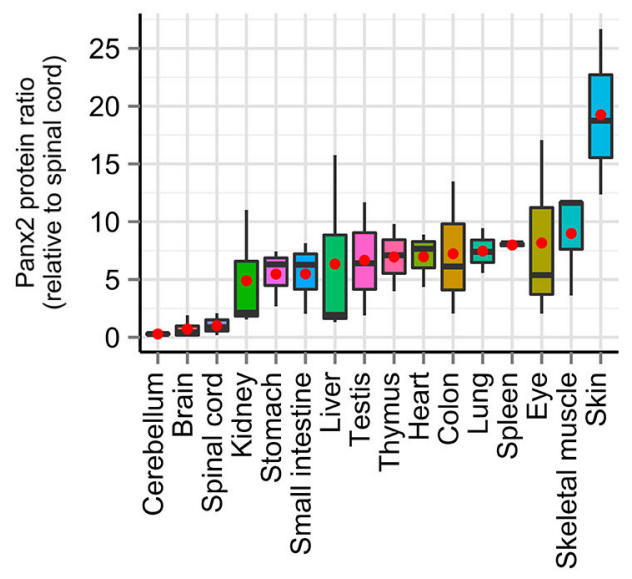

lane by the total fluorescent density measured from the spinal cord lane on the corresponding NTC membrane (LN, third panel). Normalized Panx2 protein ratios were expressed relative to Panx2 levels found in the spinal cord (fourth panel). (B) Panx2 protein ratios were calculated from three different mice (relative to spinal cord, red dots represent mean values). Panx2 protein levels were lower in the CNS than any other tissues.

\section{A}

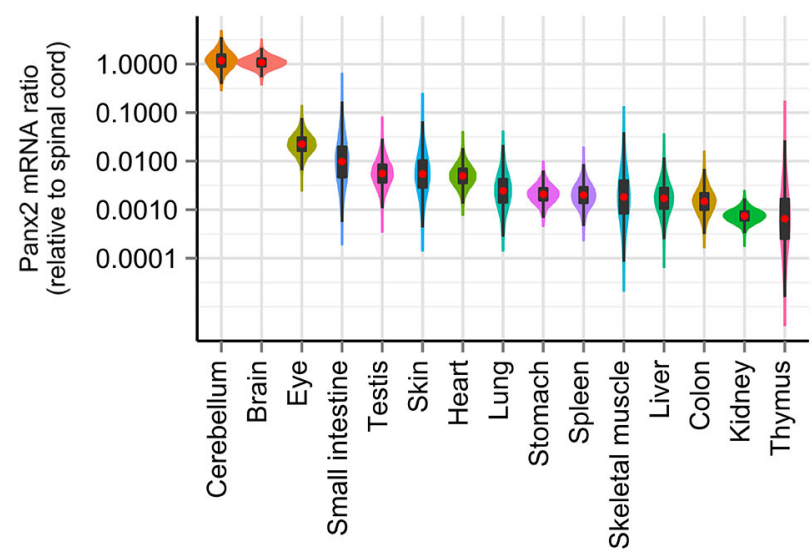

B

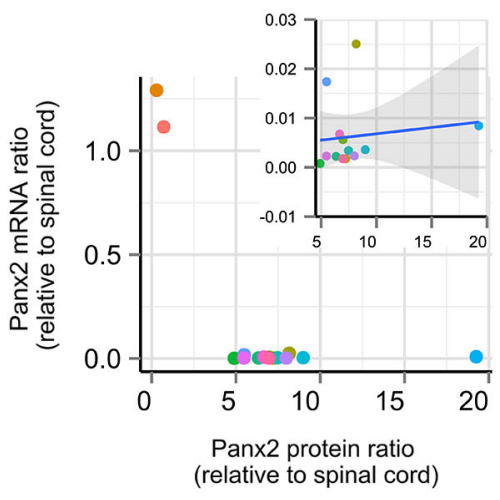

FIGURE 4 | Panx2 transcriptional activity does not correlate with protein levels. (A) Panx2 mRNA levels were measured by real-time qPCR in 16 tissues and expressed relative to Panx2 mRNA levels found in the spinal cord. Error propagation was estimated by a Monte Carlo simulation and data distribution represented using a combination of violin and box plots (red dots represent mean values). Data were plotted on a logarithmic scale. Panx2 mRNA levels were several orders of magnitude higher in the CNS than in any other tissues. (B) Panx2 protein and mRNA levels were not correlated. No significant correlation was observed even after values from the CNS were eliminated (inset). normalization strategy was employed to control for even loading as previously described (Ladner et al., 2004; Gürtler et al., 2013). Briefly, we incorporated TCE in the gel formulation which, upon ultraviolet (UV) irradiation, catalyzes a covalent reaction with tryptophan residues. This reaction emits fluorescence that can be imaged and documented in gel and following protein transfer on membranes (Ladner et al., 2004; Gürtler et al., 2013). The Panx2 staining density for each tissue was then normalized against the intensity of the TCE-fluorescence measured for the entire lane after protein transfer on nitrocellulose membrane
(Figure 3A). Our data indicate that Panx2 protein is present at substantial levels in every tissue studied (Figures 3A,B). More surprisingly, in contradiction with current predictions, Panx2 protein was lower in the nervous system than in any other tissues (Figure 3B).

\section{TRANSCRIPTIONAL ACTIVITY DOES NOT PREDICT Panx2 PROTEIN LEVELS}

Gene profiling studies have reported that Panx 2 mRNA expression is largely restricted to the CNS in human (Baranova et al., 
A

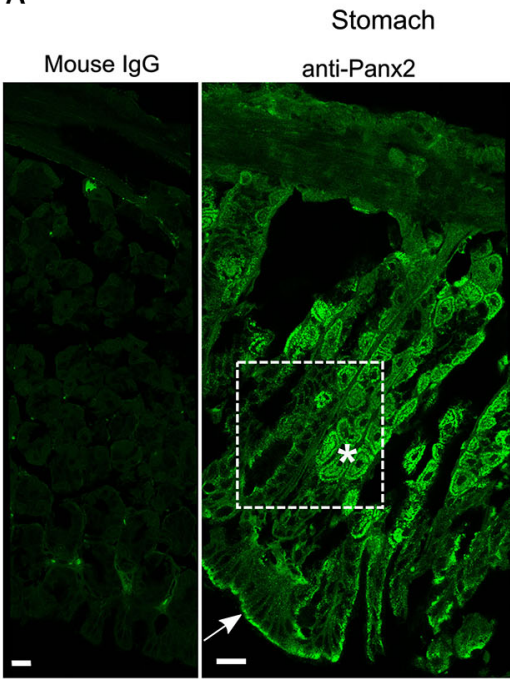

C

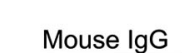

Colon anti-Panx2

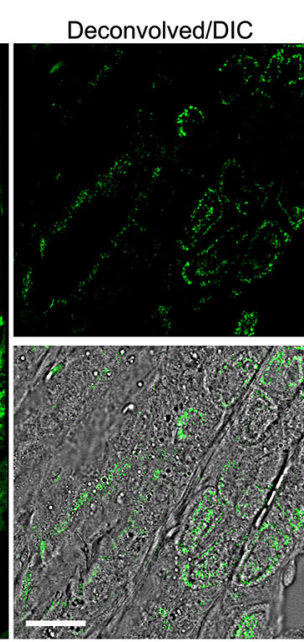

Deconvolved/DIC

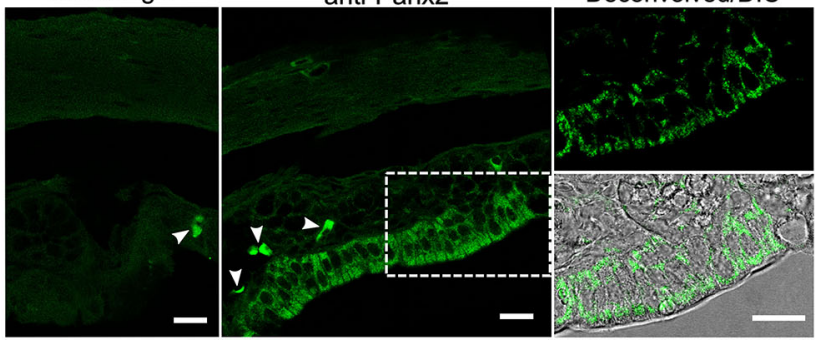

B

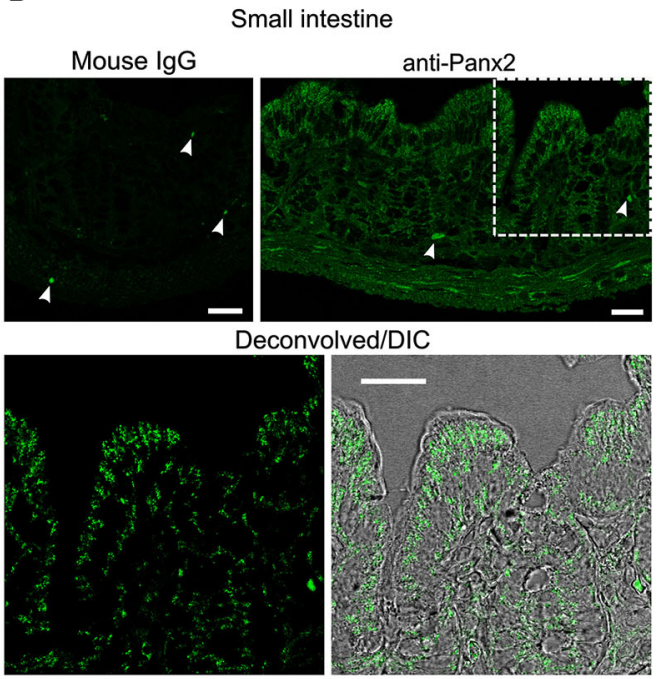

D
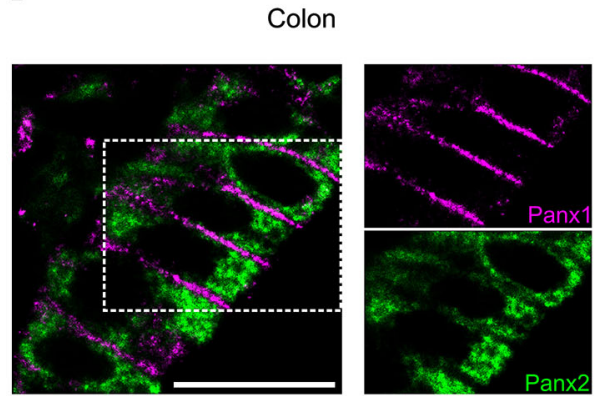

FIGURE 5 | Panx2 protein is expressed in the gastrointestinal tract. Sections of mouse stomach (A) small intestine (B) and colon (C) were stained with an immunoglobulin from non-immunized mouse (Mouse lgG panels) or the N121A/1 monoclonal anti-Panx2 antibody (anti-Panx2 and

Deconvolved/DIC panels). Panx2 protein was heavily expressed in the parietal (asterisk) and epithelial (arrow) cells of the stomach (A) and the epithelial cells of the small (B) and large (C) intestine. Panx2 distribution was primarily perinuclear and cytoplasmic. No specific staining was observed with the $\lg G$ from non-immunized mouse. Putative lymphocytes expressing endogenous immunoglobulins were occasionally labeled by the anti-mouse secondary antibody (arrowheads). (D) Panx1 and Panx2 showed distinct subcellular distribution in the colon. Scale bars: $20 \mu \mathrm{m}$.
2004), rat and mouse (Bruzzone et al., 2003; Dvoriantchikova et al., 2006) and zebrafish (Zoidl et al., 2008; Bond et al., 2012) but a similar profiling study has not been completed in mouse. To determine whether our observations on Panx2 protein expression could be explained by species-specific Panx 2 transcriptional activity, we compared the Panx 2 transcription profile using RNA isolated from 16 mouse tissues, reverse-transcribed into cDNA and analyzed by real-time qPCR. Although primers were designed to span an exon junction, end-point PCR was initially performed using non-transcribed RNA as template to confirm the absence of genomic DNA amplification (data not shown). We also tested the specificity of our primer pair by visualizing the amplification product by gel electrophoresis and by analyzing the amplicon's melting curve (data not shown). Our results are in accordance with previous studies (Bruzzone et al., 2003; Baranova et al., 2004; Dvoriantchikova et al., 2006; Zoidl et al., 2008; Bond et al., 2012) and showed that Panx2 transcriptional activity largely predominates in the CNS (Figure 4A). Panx2 transcript levels detected in non-neural tissues were several orders of magnitude lower than in the CNS (Figure 4A). Furthermore, we demonstrated that there is no significant correlation between Panx2 transcript and corresponding protein levels (Figure 4B).

Our results showed that Panx 2 mRNA and protein levels are not correlated when compared across different tissues but does not exclude a possible correlation within a specific tissue as opposed to between different tissues. This scenario appears unlikely however as we have shown that Panx2 protein levels remain surprisingly constant in the brain over a developmental period during which Panx2 mRNA levels have been shown to be temporally up-regulated (data not shown) (Vogt et al., 2005). Overall, these results suggest that regulatory mechanisms unrelated to transcriptional activity must also control Panx2 protein levels and indicate that Panx2 protein levels cannot be directly inferred from the quantification of its transcript levels.

\section{Panx2 PROTEIN IS LOCALIZED TO CYTOPLASMIC COMPARTMENTS}

We next characterized the expression and distribution of Panx2 in different tissues by immunofluorescence. In the gastrointestinal 


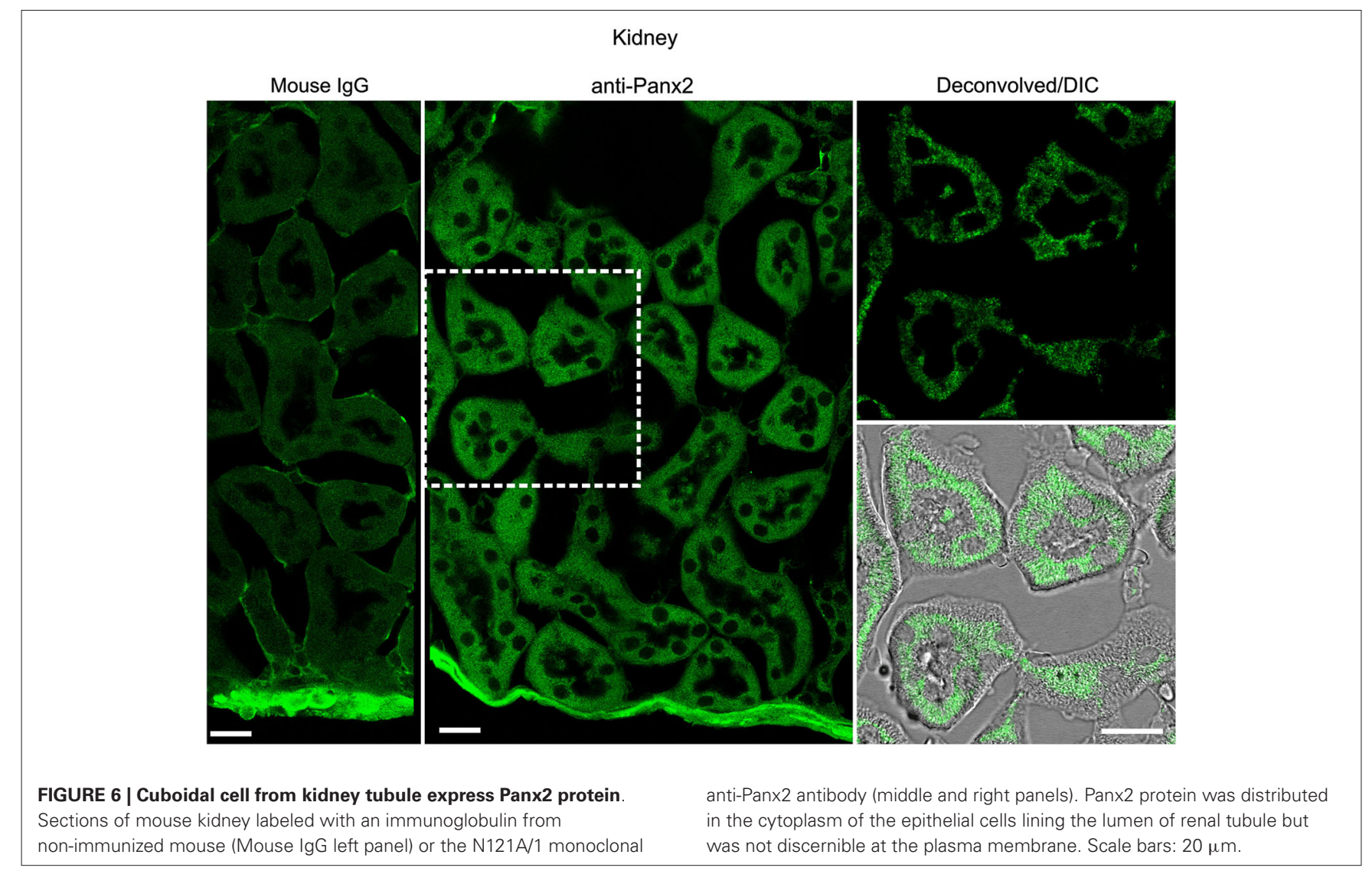

tract, an important population of glandular and epithelial cells displayed strong Panx2 immunoreactivity (Figure 5). Parietal cells, which secrete gastric acid, and the apical surface of epithelial cells of the stomach were strongly reactive for Panx2 (Figure 5A). In the small and large intestine, a population of columnar epithelial cells were also strongly reactive for Panx2 (Figures 5B,C). As Panx1 has also been shown to be expressed in the columnar epithelial cells of the human colon (Diezmos et al., 2013), we tested whether Panx1 and Panx2 could colocalize in these cell types. Interestingly, Panx1 and Panx2 did not co-localize but showed quite different subcellular distribution patterns (Figure 5D). Panx1 expression was largely restricted to the plasma membrane between the epithelial cells. In contrast, Panx2 was not discernible at the plasma membrane but remained largely confined to the cytoplasmic area (Figure 5D).

In the kidney, cuboidal cells forming the single layered epithelium of tubules were strongly labeled (Figure 6) whereas glomeruli cells were not (data not shown). Panx2 staining was predominantly cytoplasmic and could not be detected at the plasma membrane. Similarly, germ cells from testis seminiferous tubules showed abundant perinuclear and cytoplasmic but no plasma membrane staining (Figure 7).

Panx2 immunoreactivity displayed a distinct pattern in the mouse retina (Figure 8). Photoreceptor inner segments protruding into the subretinal space were densely decorated with Panx2labeled aggregates (Figure 8). Only sparse immunoreactivity was observed in the outer nuclear layer which forms the compact layer containing photoreceptor cell bodies (Figure 8). Substantial staining was also observed in the outer plexiform layer which comprises a dense network of neuronal synapses formed between photoreceptors and bipolar and horizontal cell dendrites (Figure 8).

Despite showing lower Panx2 protein levels than any other tissues (Figure 3), Panx2 immunoreactivity was easily distinguishable by immunofluorescence in the CNS (Figure 9) and showed a complex expression pattern as previously reported (Zappalà et al., 2007). Panx2 was widely distributed in the cytoplasm of neurons throughout the CNS but was not readily detected in astrocytes in vivo (Figures 9A-C). Interestingly, we showed that the majority of primary astrocytes $(63.8 \pm 0.9 \%)$ expressed cytoplasmic Panx2 at 5 days in vitro (Figure 9D). However, the percentage of Panx2positive astrocytes rapidly declined after 10 and 15 days in vitro $(6.9 \pm 1.2 \%$ and $7.3 \pm 1.1 \%)$ hereby suggesting that Panx2 is expressed by immature but not mature astrocytes. That observation could explain the up-regulation of Panx2 expression seen in astrocytes following ischemia (Zappalà et al., 2007) as ischemia is characterized by astrocyte proliferation.

\section{DISCUSSION}

This study reveals that Panx2 protein is more ubiquitous than initially predicted. By performing real-time $\mathrm{qPCR}$ and 


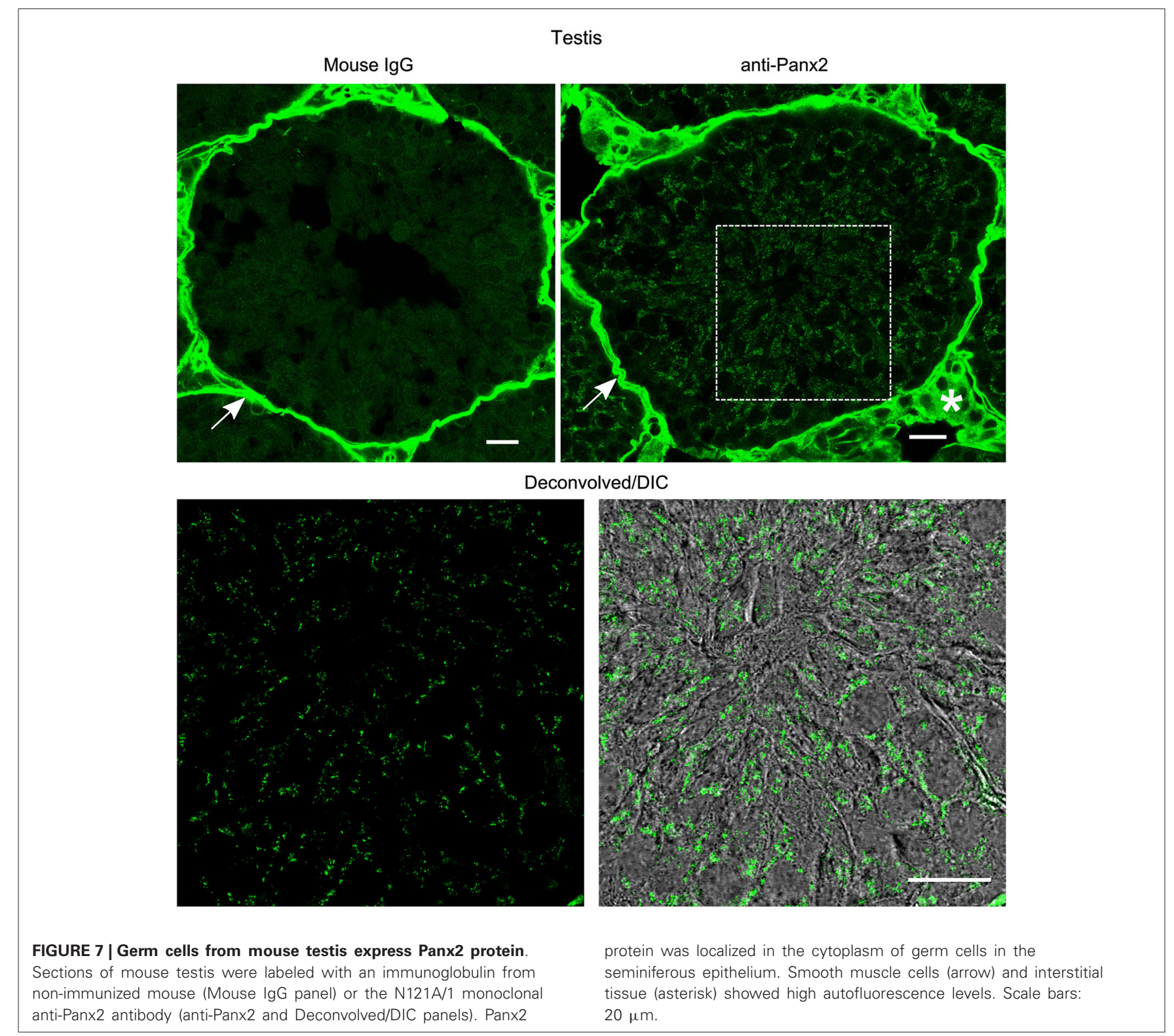

semi-quantitative Western blot analysis on a panel of mouse tissues, we showed that fluctuations in Panx2 mRNA abundance do not predict changes in Panx2 protein levels. We showed that Panx2 protein levels are surprisingly more abundant in non-neural tissues than in the CNS; an observation opposite to Panx2 transcriptional activity which is weak in non-neural tissues and largely predominant in the CNS. The ubiquitous expression of Panx2 protein suggests a more fundamental function than the CNS-specific role which was originally proposed. Although the exact function of Panx2 remains elusive, based on our in vivo immunofluorescence results we hypothesize that Panx2 channels do not significantly contribute to communication exchange between the intracellular and extracellular spaces but rather control intracellular signaling through cytoplasmic compartments.

\section{ABSENCE OF CORRELATION BETWEEN Panx2 mRNA AND PROTEIN LEVELS}

The initial Panx2 gene expression profiles were obtained from Northern blots using commercial rat (Bruzzone et al., 2003) and human (Baranova et al., 2004) mRNA. Although notable differences exist between the two studies, both groups reported that Panx 2 mRNA is largely predominant in the CNS; an observation that was subsequently confirmed in zebrafish using realtime qPCR (Zoidl et al., 2008; Bond et al., 2012). Our results show that Panx 2 mRNA follows a similar expression profile in the mouse since Panx2 transcript levels are 40 to over 1600 times higher in the CNS than in other tissues. Because of this dramatic disparity in Panx2 mRNA expression it has long been assumed that Panx2 protein was preferentially, if not exclusively, expressed in the CNS. 


\section{Retina}

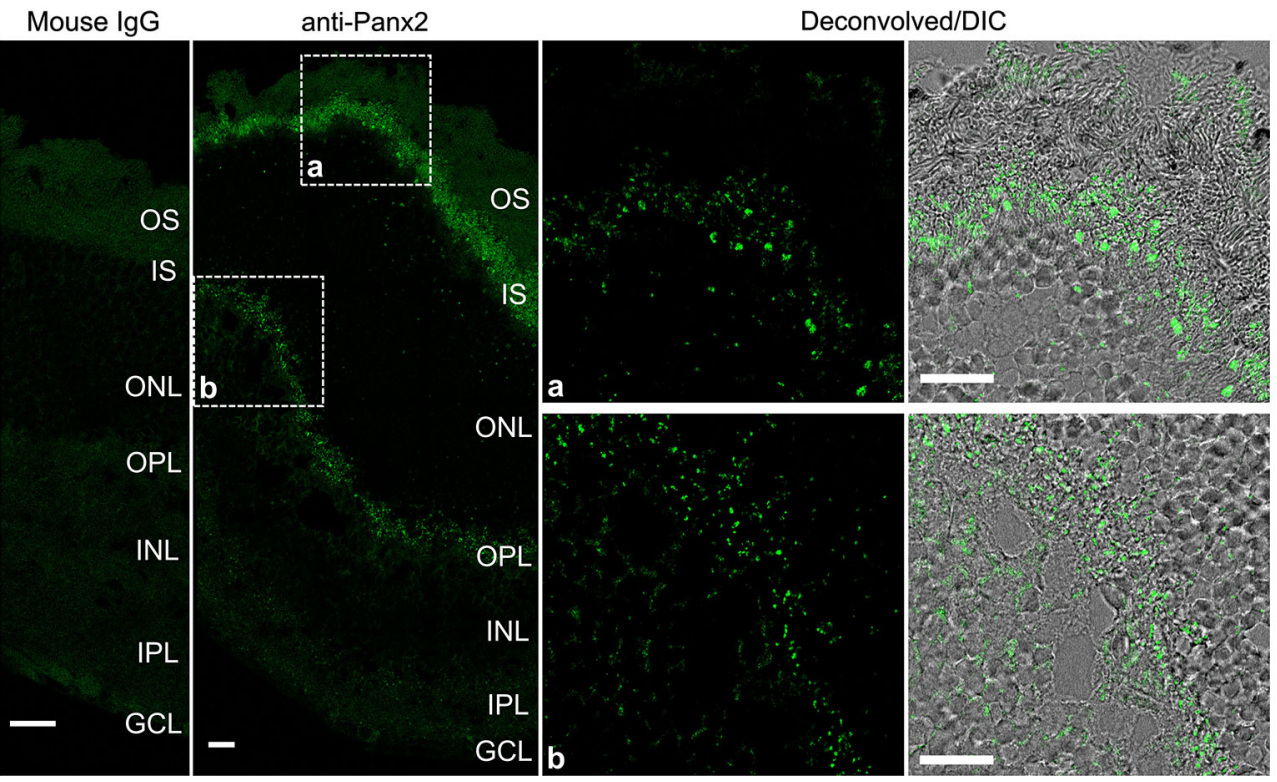

FIGURE 8 | Panx2 protein is expressed in the photoreceptor inner segment and outer plexiform layer of the mouse retina. Sections from mouse retina were labeled with an immunoglobulin from non-immunized mouse (Mouse IgG panel) or the N121A/1 monoclonal anti-Panx2 antibody (anti-Panx2 and Deconvolved/DIC panels). Panx2 protein was primarily expressed in the photoreceptor inner segment (IS) (inset a) or the outer plexiform layer (OPL) (inset b). Panx2 clustered in small to large aggregates which appeared to be primarily cytoplasmic However, because of the high degree of cellular compaction we could not reach definitive conclusions regarding Panx2 subcellular distribution in the retina. OS: photoreceptor outer segment, IS: photoreceptor inner segment, ONL: outer nuclear layer, OPL: outer plexiform layer, INL: inner nuclear layer, IPL: inner plexiform layer, GCL: ganglion cell layer. Scale bars: $20 \mu \mathrm{m}$.
However, in almost every organism steady-state transcript concentrations only partially correlate with protein expression levels (de Sousa Abreu et al., 2009) and the assumption that transcripts can predict protein abundances has been heavily challenged. Post-transcriptional regulatory mechanisms have overwhelming influence on changes observed at the proteome level (Foss et al., 2011) and protein levels cannot be accurately extrapolated from transcript levels because several factors unrelated to transcriptional control also directly influence protein levels. For example, protein degradation rate has been shown to influence the correlation between transcripts and corresponding protein levels as stable proteins are less affected by perturbations in mRNA levels than proteins with high turnover rates (Raj et al., 2006). Hence, the long half-life of Panx proteins (Penuela et al., 2007) could efficiently buffer important fluctuations in mRNA levels and decrease the impact of Panx2 transcripts on Panx2 protein levels. Bearing this information in mind, it is safe to affirm that variations of Panx 2 transcript levels should be interpreted restrictively, without assuming equivalent changes at the protein level.

Mass-spectrometry-based proteomics can perform large-scale unbiased analyses of biological systems and examine which genes are translated into proteins in specific tissues. Recently, two groups assembled and published mass-spectrometry-based drafts of the human proteome into databases available online for real-time analysis (Kim et al., 2014; Wilhelm et al., 2014).
Interestingly, unique Panx2 peptides were identified in the ileum, colon and ovary (Wilhelm et al., 2014) as well as the gut, spinal cord, urinary bladder, liver, ovary, testis and prostate (Kim et al., 2014). Although substantial improvements are still needed to achieve a complete and quantitative proteome coverage, these independent studies nonetheless corroborate our results and demonstrate that Panx2 protein expression is not restricted to the CNS.

It is important to note that Panx2 protein ratios showed high variability in some tissues (Figure 3B). This is more likely attributable to the limited dynamic range of the chemiluminescence technique that was used for the quantification of Panx2 protein expression. An alternative would have been to use a ratiometric analysis based on infrared detection of protein bands to increase the linear detection range and increased reproducibility (Zellner et al., 2008).

\section{Panx2: A CYTOPLASMIC UNUSUAL SUSPECT}

Technical reasons such as prevalent autofluorescence prevented the analysis of certain tissues by immunofluorescence. Nonetheless, our study shows that Panx2 protein was heavily distributed in the cytoplasmic compartment and could not be readily detected at the plasma membrane in all tissues analyzed by immunofluorescence ( 9 out of 16) or in cultured primary astrocytes expressing endogenous Panx2 protein. Previous studies had reported cytoplasmic Panx2 in transfected overexpression 


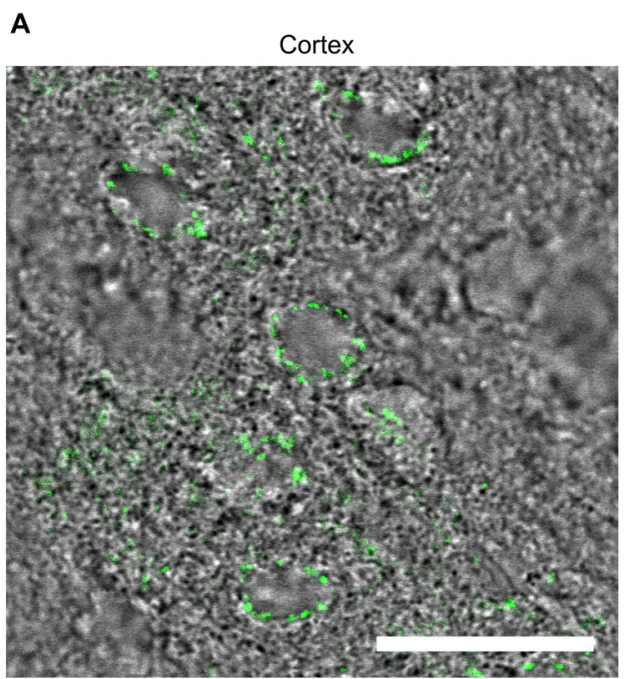

C

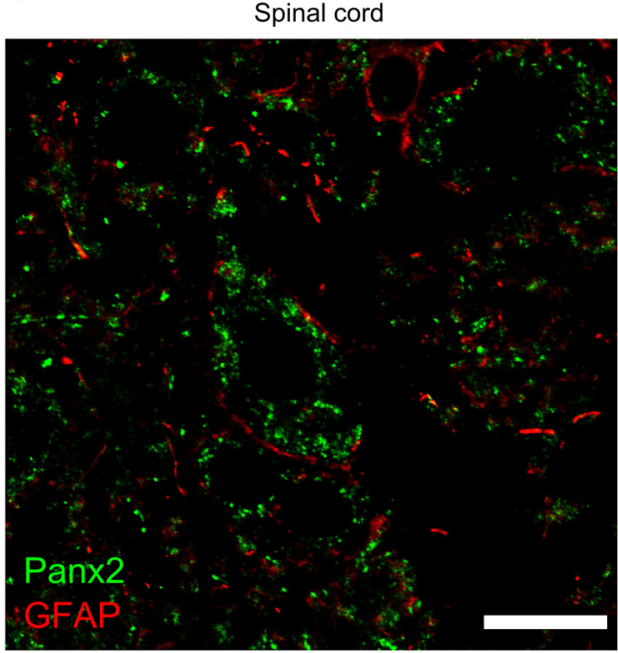

FIGURE 9 | Panx2 protein localizes in the cytoplasm of CNS neurons.

Pan $\times 2$ heavily labeled the cytoplasm, but not the plasma membrane, of

cortical neurons (A) Purkinje cells (B) and spinal cord motoneurons (C). Panx2

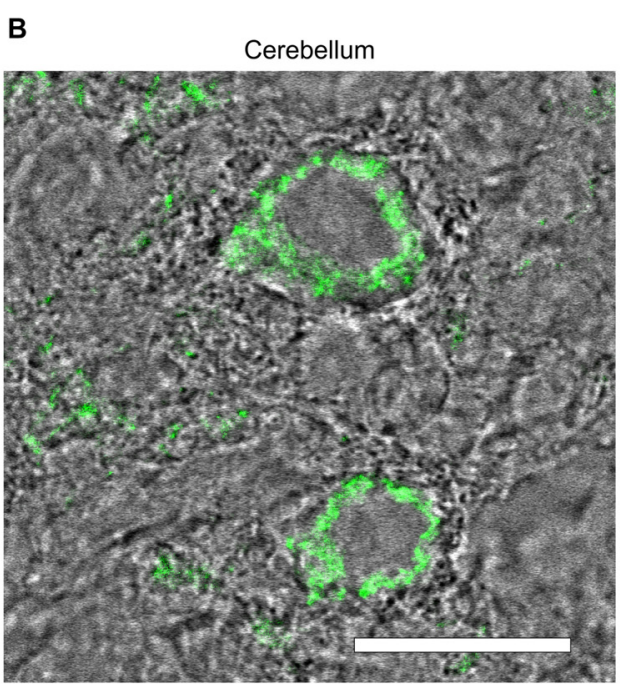

D

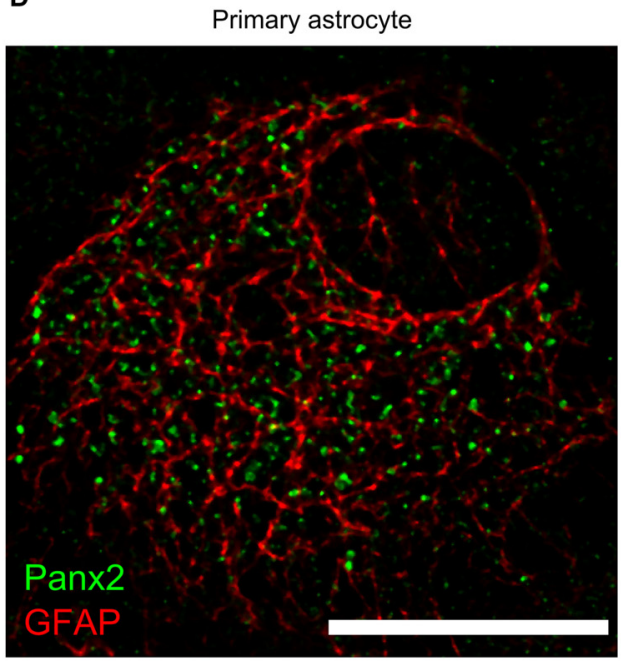

was not detected in GFAP-positive astrocytes in the brain (data not shown) or the spinal cord (C) but was detected in over $60 \%$ of primary astrocytes cultured for 5 days (D). Scale bars: $20 \mu \mathrm{m}$ systems (Lai et al., 2009; Penuela et al., 2009; Bhalla-Gehi et al., 2010) or in neurons and neural progenitor cells (Zappalà et al., 2007; Swayne et al., 2010) but we are the first group to identify endogenous cytoplasmic Panx2 in such a large variety of tissues.

The unique intracellular distribution of Panx2 protein is in striking contrast with Panx1 and Panx3 proteins which are primarily localized at the plasma membrane (Penuela et al., 2007, 2009; Bhalla-Gehi et al., 2010). The cellular localization of Panx proteins is influenced by glycosylation (Penuela et al., 2009). All three Panx paralogs are glycosylated to a high mannose form in the endoplasmic reticulum (ER; Penuela et al., 2009; Bhalla-Gehi et al., 2010) but interestingly only Panx1 and Panx3 proteins form complex glycoprotein species requiring post-translational modifications occurring in the Golgi (Penuela et al., 2009; Bhalla-Gehi et al., 2010). Panxl and
Panx3 proteins follow a COPII-dependent ER to Golgi secretory pathway prior to being trafficked to the plasma membrane (Bhalla-Gehi et al., 2010). In contrast, the absence of complex glycosylated Panx2 suggests Panx2 protein follows a different trafficking pathway which might not involve transition through the Golgi and subsequent trafficking to the plasma membrane. Intriguingly, Panx2 has been shown to colocalize with the endolysosomal enriched mannose-6-phosphate receptor in N2a neuroblastoma cells expressing Panx2 tagged with GFP (Wicki-Stordeur et al., 2013). However, the study used transient overexpression of tagged Panx 2 protein which might have resulted in the accumulation of misfolded or misassembled proteins and increased the likelihood of artifactual missorting in endomembrane compartments. Therefore, additional localization studies detecting endogenous Panx2 protein using a combination of different approaches are still needed 
for the accurate identification of Panx2-positive cytoplasmic compartments.

Others have detected putative Panx2 at the plasma membrane of mature primary hippocampal neurons (Swayne et al., 2010) or in cell types overexpressing Panx2 (Ambrosi et al., 2010). The ectopic expression of Panx1 and Panx2 in NRK cells has also been shown to increase Panx2 trafficking to the plasma membrane (Penuela et al., 2009). However, the physiological relevance of this increase in Panx2 at the plasma membrane is unclear because Panx1/Panx2 heteromeric channels are unstable (Ambrosi et al., 2010). Although we cannot exclude the possibility that undetectable levels of Panx2 are distributed at the plasma membrane in some cell types, we conclude that under physiological conditions Panx2 protein is primarily localized in the cytoplasmic compartment in most, if not all, tissues.

Gap junctions have traditionally been described as plasma membrane channels connecting the cytoplasm of adjacent cells or controlling the exchange of small molecules between the intracellular and extracellular spaces. Our results suggest that a different model must apply to Panx2 because its range of action seems to be restricted to the cytoplasmic milieu. Consequently, we hypothesize that Panx2 can modulate cell activity through nonconventional routes and novel intracellular signaling pathways. In that aspect, it is interesting to note that over-expression of Panx1 and Panx3 can form calcium permeable channels in the ER (Vanden Abeele et al., 2006; Ishikawa et al., 2011). As over-expression of Panx2 in C6 cells showed a prominent signal overlap with the ER (Lai et al., 2009) it is possible that Panx2 can also modulate ER calcium signaling. Moreover, although an essential property of gap junction proteins is their ability to oligomerize to form transmembrane channels, it should be emphasized that gap junctions also have channel-independent functions. For example, connexin 43 ( Cx43) has recently been shown to control the biogenesis of autophagosomes through the sequestration of several autophagyrelated proteins (Bejarano et al., 2014); a function independent of Cx43 channel activity. Since Panx2 has a long C-terminal tail (301 a.a) it is reasonable to suggest that protein-protein interactions involving its C-terminus are likely to play an important role in the function of Panx2. However, until the exact nature of Panx2 subcellular compartment remains unknown, formulating hypothesis regarding the function of Panx2 remains rather difficult.

Our understanding of Panx2 protein currently assumes that Panx2 function can be extrapolated from our knowledge of the other Panx proteins. More precisely, Panx2 is often perceived as a CNS-specific protein assuming a role complementary, if not redundant, to the function of Panxl channel. However, our study shows that this assumption is misleading and unlikely to increase our knowledge on any of the Panx channels. Prior to our work, several studies investigating the role of Panx channels outside of the CNS focused exclusively on Panx1 and Panx3 but completely neglected the potential implication of Panx2. As our study shows that Panx2 protein expression is more ubiquitous than initially predicted it would be interesting to revisit these original studies while taking into account the presence of Panx2. This is especially important in the context of Panx1 knockout mice since the deletion of Panx1 could have compensatory effects by altering the expression level of Panx2. Another cautionary note needs to be highlighted regarding the techniques that are currently used to assay Panx2 functionality. Several studies use patchclamping of the plasma membrane to address the functionality of Panx2 channels (for example see Bargiotas et al., 2011; Poon et al., 2014). Although we cannot totally exclude the presence of Panx2 at the plasma membrane, our study nonetheless shows that Panx2 protein is predominantly in cytoplasmic compartments. Consequently, Panx2 channel properties cannot be solely investigated through electrophysiological recordings at the plasma membrane.

\section{ACKNOWLEDGMENTS}

We would like to thank Drs. Stephen Bond and Moises FreitasAndrade for constructive comments during the preparation of this manuscript and Dr. Hoa T. Le for the preparation of primary mouse astrocytes. This work was supported by the Natural Sciences and Engineering Research Council of Canada (NSERC) Alexander Graham Bell Canada Graduate Scholarship (Maxence Le Vasseur) and the Canadian Institute of Health Research (Christian C. Naus, Wun-Chey Sin). Christian Naus holds a Canada Research Chair.

\section{REFERENCES}

Ambrosi, C., Gassmann, O., Pranskevich, J. N., Boassa, D., Smock, A., Wang, J., et al. (2010). Pannexin 1 and pannexin 2 channels show quaternary similarities to connexons and different oligomerization numbers from each other. J. Biol. Chem. 285, 24420-24431. doi: 10.1074/jbc.m110.115444

Baranova, A., Ivanov, D., Petrash, N., Pestova, A., Skoblov, M., Kelmanson, I., et al. (2004). The mammalian pannexin family is homologous to the invertebrate innexin gap junction proteins. Genomics 83, 706-716. doi: 10.1016/j.ygeno.2003. 09.025

Barbe, M. T. (2006). Cell-cell communication beyond connexins: the pannexin channels. Physiology 21, 103-114. doi: 10.1152/physiol.00048.2005

Bargiotas, P., Krenz, A., Hormuzdi, S. G., Ridder, D. A., Herb, A., Barakat, W., et al. (2011). Pannexins in ischemia-induced neurodegeneration. Proc. Natl. Acad. Sci. U S A 108, 20772-20777. doi: 10.1073/pnas.1018262108

Bejarano, E., Yuste, A., Patel, B., Stout, R. F. Jr., Spray, D. C., and Cuervo, A. M. (2014). Connexins modulate autophagosome biogenesis. Nat. Cell Biol. 16, 401414. doi: $10.1038 /$ ncb2934

Bhalla-Gehi, R., Penuela, S., Churko, J. M., Shao, Q., and Laird, D. W. (2010). Pannexin1 and pannexin3 delivery, cell surface dynamics and cytoskeletal interactions. J. Biol. Chem. 285, 9147-9160. doi: 10.1074/jbc.m109.082008

Boassa, D., Ambrosi, C., Qiu, F., Dahl, G., Gaietta, G., and Sosinsky, G. (2007). Pannexin1 channels contain a glycosylation site that targets the hexamer to the plasma membrane. J. Biol. Chem. 282, 31733-31743. doi: 10.1074/jbc. m702422200

Bond, S. R., Wang, N., Leybaert, L., and Naus, C. C. (2012). Pannexin 1 ohnologs in the teleost lineage. J. Membr. Biol. 245, 483-493. doi: 10.1007/s00232-0129497-4

Bruzzone, R., Hormuzdi, S. G., Barbe, M. T., Herb, A., and Monyer, H. (2003). Pannexins, a family of gap junction proteins expressed in brain. Proc. Natl. Acad. Sci. US A 100, 13644-13649. doi: 10.1073/pnas.2233464100

de Sousa Abreu, R., Penalva, L. O., Marcotte, E. M., and Vogel, C. (2009). Global signatures of protein and mRNA expression levels. Mol. Biosyst. 5, 1512-1526. doi: 10.1039/b908315d

Diezmos, E. F., Sandow, S. L., Markus, I., Shevy Perera, D., Lubowski, D. Z., King, D. W., et al. (2013). Expression and localization of pannexin-1 hemichannels in human colon in health and disease. Neurogastroenterol. Motil. 25, e395-e405. doi: $10.1111 / \mathrm{nmo} .12130$

Dvoriantchikova, G., Ivanov, D., Panchin, Y., and Shestopalov, V. I. (2006). Expression of pannexin family of proteins in the retina. FEBS Lett. 580, 2178-2182. doi: 10.1016/j.febslet.2006.03.026 
Foss, E. J., Radulovic, D., Shaffer, S. A., Goodlett, D. R., Kruglyak, L., and Bedalov, A. (2011). Genetic variation shapes protein networks mainly through non-transcriptional mechanisms. PLoS Biol. 9:e1001144. doi: 10.1371/journal. pbio. 1001144

Gassmann, M., Grenacher, B., Rohde, B., and Vogel, J. (2009). Quantifying western blots: pitfalls of densitometry. Electrophoresis 30, 1845-1855. doi: 10.1002/elps. 200800720

Guescini, M., Sisti, D., Rocchi, M. B. L., Stocchi, L., and Stocchi, V. (2008). A new real-time PCR method to overcome significant quantitative inaccuracy due to slight amplification inhibition. BMC Bioinformatics 9:326. doi: 10.1186/14712105-9-326

Gürtler, A., Kunz, N., Gomolka, M., Hornhardt, S., Friedl, A. A., McDonald, K., et al. (2013). Stain-free technology as a normalization tool in western blot analysis. Anal. Biochem. 433, 105-111. doi: 10.1016/j.ab.2012.10.010

Ishikawa, M., Iwamoto, T., Nakamura, T., Doyle, A., Fukumoto, S., and Yamada, Y. (2011). Pannexin 3 functions as an $\mathrm{ER} \mathrm{Ca}(2+)$ channel, hemichannel and gap junction to promote osteoblast differentiation. J. Cell Biol. 193, 1257-1274. doi: $10.1083 /$ jcb. 201101050

Kim, M.-S., Pinto, S. M., Getnet, D., Nirujogi, R. S., Manda, S. S., Chaerkady, R., et al. (2014). A draft map of the human proteome. Nature 509, 575-581. doi: 10 1038/nature 13302

Kurtenbach, S., Prochnow, N., Kurtenbach, S., Klooster, J., Zoidl, C., Dermietzel, R., et al. (2013). Pannexin1 channel proteins in the zebrafish retina have shared and unique properties. PloS One 8:e77722. doi: 10.1371/journal.pone.00 77722

Ladner, C. L., Yang, J., Turner, R. J., and Edwards, R. A. (2004). Visible fluorescent detection of proteins in polyacrylamide gels without staining. Anal. Biochem. 326, 13-20. doi: 10.1016/j.ab.2003.10.047

Lai, C., Bechberger, J., and Naus, C. (2009). Pannexin2 as a novel growth regulator in C6 glioma cells. Oncogene 28, 4402-4408. doi: 10.1038/onc.2009.283

Lai, C. P. K., Bechberger, J. F., Thompson, R. J., MacVicar, B. A., Bruzzone, R., and Naus, C. C. (2007). Tumor-suppressive effects of pannexin 1 in C6 glioma cells. Cancer Res. 67, 1545-1554. doi: 10.1158/0008-5472.can-06-1396

Le, H. T., Sin, W. C., Lozinsky, S., Bechberger, J., Vega, J. L., Guo, X. Q., et al. (2014). Gap junction intercellular communication mediated by connexin 43 in astrocytes is essential for their resistance to oxidative stress. J. Biol. Chem. 289, 1345-1354. doi: 10.1074/jbc.m113.508390

Panchin, Y. V. (2005). Evolution of gap junction proteins-the pannexin alternative. J. Exp. Biol. 208, 1415-1419. doi: 10.1242/jeb.01547

Panchin, Y., Kelmanson, I., Matz, M., Lukyanov, K., Usman, N., and Lukyanov, S. (2000). A ubiquitous family of putative gap junction molecules. Curr. Biol. 10, R473-R474. doi: 10.1016/s0960-9822(00)00576-5

Penuela, S., Bhalla, R., Gong, X. Q., Cowan, K. N., Celetti, S. J., Cowan, B. J., et al. (2007). Pannexin 1 and pannexin 3 are glycoproteins that exhibit many distinct characteristics from the connexin family of gap junction proteins. J. Cell Sci. 120, 3772-3783. doi: 10.1242/jcs.009514

Penuela, S., Bhalla, R., Nag, K., and Laird, D. W. (2009). Glycosylation regulates pannexin intermixing and cellular localization. Mol. Biol. Cell 20, 4313-4323. doi: 10.1091/mbc.e09-01-0067

Pfaffl, M. W. (2001). A new mathematical model for relative quantification in realtime RT-PCR. Nucleic Acids Res. 29:e45. doi: 10.1093/nar/29.9.e45

Poon, I. K. H., Chiu, Y.-H., Armstrong, A. J., Kinchen, J. M., Juncadella, I. J., Bayliss, D. A., et al. (2014). Unexpected link between an antibiotic, pannexin channels and apoptosis. Nature 507, 329-334. doi: 10.1038/nature13147

Raj, A., Peskin, C. S., Tranchina, D., Vargas, D. Y., and Tyagi, S. (2006). Stochastic mRNA synthesis in mammalian cells. PLoS Biol. 4:e309. doi: 10.1371/journal. pbio.0040309

Ritz, C., and Spiess, A.-N. (2008). qpcR: an R package for sigmoidal model selection in quantitative real-time polymerase chain reaction analysis. Bioinformatics 24 1549-1551. doi: 10.1093/bioinformatics/btn227
Sahu, G., Sukumaran, S., and Bera, A. K. (2014). Pannexins form gap junctions with electrophysiological and pharmacological properties distinct from connexins. Sci. Rep. 4:4955. doi: 10.1038/srep04955

Sosinsky, G. E., Boassa, D., Dermietzel, R., Duffy, H. S., Laird, D. W., MacVicar, B., et al. (2011). Pannexin channels are not gap junction hemichannels. Channels (Austin) 5, 193-197. doi: 10.4161/chan.5.3.15765

Spiess, A.-N., Feig, C., and Ritz, C. (2008). Highly accurate sigmoidal fitting of realtime PCR data by introducing a parameter for asymmetry. BMC Bioinformatics 9:221. doi: 10.1186/1471-2105-9-221

Swayne, L. A., Sorbara, C. D., and Bennett, S. A. L. (2010). Pannexin 2 is expressed by postnatal hippocampal neural progenitors and modulates neuronal commitment. J. Biol. Chem. 285, 24977-24986. doi: 10.1074/jbc.m110.130054

Vanden Abeele, F., Bidaux, G., Gordienko, D., Beck, B., Panchin, Y. V., Baranova, A. V., et al. (2006). Functional implications of calcium permeability of the channel formed by pannexin 1. J. Cell Biol. 174, 535-546. doi: 10.1083/jcb. 200601115

Vogt, A., Hormuzdi, S. G., and Monyer, H. (2005). Pannexin1 and pannexin2 expression in the developing and mature rat brain. Brain Res. Mol. Brain Res. 141, 113-120. doi: 10.1016/j.molbrainres.2005.08.002

Vonesch, C., and Unser, M. (2008). A fast thresholded landweber algorithm for wavelet-regularized multidimensional deconvolution. IEEE Trans. Image Process. 17, 539-549. doi: 10.1109/tip.2008.917103

Wicki-Stordeur, L. E., Boyce, A. K. J., and Swayne, L. A. (2013). Analysis of a pannexin 2-pannexin 1 chimeric protein supports divergent roles for pannexin C-termini in cellular localization. Cell Commun. Adhes. 20, 73-79. doi: 10. 3109/15419061.2013.791681

Wilhelm, M., Schlegl, J., Hahne, H., Gholami, A. M., Lieberenz, M., Savitski, M. M., et al. (2014). Mass-spectrometry-based draft of the human proteome. Nature 509, 582-587. doi: 10.1038/nature13319

Zappalà, A., Li Volti, G., Serapide, M. F., Pellitteri, R., Falchi, M., La Delia, F., et al. (2007). Expression of pannexin2 protein in healthy and ischemized brain of adult rats. Neuroscience 148, 653-667. doi: 10.1016/j.neuroscience.2007. 06.028

Zellner, M., Babeluk, R., Diestinger, M., Pirchegger, P., Skeledzic, S., and Oehler, R. (2008). Fluorescence-based western blotting for quantitation of protein biomarkers in clinical samples. Electrophoresis 29, 3621-3627. doi: 10.1002/elps. 200700935

Zhang, H., Chen, Y., and Zhang, C. (2012). Patterns of heterogeneous expression of pannexin 1 and pannexin 2 transcripts in the olfactory epithelium and olfactory bulb. J. Mol. Histol. 43, 651-660. doi: 10.1007/s10735-012-9443-x

Zoidl, G., Kremer, M., Zoidl, C., Bunse, S., and Dermietzel, R. (2008). Molecular diversity of connexin and pannexin genes in the retina of the zebrafish danio rerio. Cell Commun. Adhes. 15, 169-183. doi: 10.1080/15419060802014081

Conflict of Interest Statement: The authors declare that the research was conducted in the absence of any commercial or financial relationships that could be construed as a potential conflict of interest.

Received: 20 August 2014; accepted: 03 November 2014; published online: 25 November 2014.

Citation: Le Vasseur M, Lelowski J, Bechberger JF, Sin W-C and Naus CC (2014) Pannexin 2 protein expression is not restricted to the CNS. Front. Cell. Neurosci. 8:392. doi: 10.3389/fncel.2014.00392

This article was submitted to the journal Frontiers in Cellular Neuroscience.

Copyright (C) 2014 Le Vasseur, Lelowski, Bechberger, Sin and Naus. This is an openaccess article distributed under the terms of the Creative Commons Attribution License (CC BY). The use, distribution and reproduction in other forums is permitted, provided the original author(s) or licensor are credited and that the original publication in this journal is cited, in accordance with accepted academic practice. No use, distribution or reproduction is permitted which does not comply with these terms. 